\title{
A escultura cinética de Mary Vieira e a conexão entre arte e tecnologia
}

ALMERINDA DA SILVA LOPES ${ }^{1}$

1 Doutora em Artes Visuais pelo Programa de Comunicação e Semiótica da Pontifícia Universidade Católica de São Paulo. Professora e Pesquisadora de Teoria, Crítica e História da Arte do Programa de Pós Graduação em Artes da Universidade Federal do Espírito Santo. Bolsista de Produtividade do CNPq, curadora independente, autora de livros e outras publicações na área, com foco da investigação na arte moderna e contemporânea. 


\section{- RESUMO}

Este artigo analisa a obra cinética de Mary Vieira que, na década de 1940, antes de se transferir definitivamente para a Europa, construiu em Minas Gerais as primeiras obras dotadas de movimento. Tornava-se pioneira no Brasil e no mundo neste gênero de escultura, concretizando assim uma antiga aspiração: retirar a arte de sua tradicional imobilidade. Nesse sentido, reflete-se, também, sobre alguns investimentos e premissas anteriores, que contaminaram e impulsionaram essa e outros artistas a empreender pesquisas que iriam revolucionar a arte do século passado.

\section{- PALAVRAS-CHAVE}

Arte cinética, arte e tecnologia, Mary Vieira, interatividade.

\section{ABSTRACT}

This article analyses the kinetic works of Mary Vieira that, in de 1940's decade, prior to her definitive moving to Europe, built in Minas Gerais the first gifted works of movement. It became pioneer in Brazil and around the world as this kind of sculpture, coming true an ancient aspiration: taking from the art its traditional immobility. In that sense, it reflects upon some investments and previous assumptions that infected and boosted this and other artists to undertake researchs that revolutionized the art from the last century.

\section{- KEYWORDS}

Kinetic art, art and technologgy, Mary Vieira, interactivity.

\section{Introdução}

A partir da Revolução Industrial, instaurava-se um processo de crise e de ruptura com os valores espirituais e os paradigmas estéticos do passado. Gerava-se, em contrapartida, um clima propício ao capitalismo e ao racionalismo, difundia-se a crença na ideia de progresso e em uma nova ordem social e econômica pautada no conforto e na liberdade individual. A esse "espírito positivo", de base instrumental e pragmática, também iria se vincular a ideia de autonomia do fenômeno artístico e instituir-se um novo estatuto social para o artista. Este investiria, assim, na busca de eficiência técnica, visando aumentar a produção e a rentabilidade econômica, o que significa que, de maneira utópica e ambivalente, a arte iria se colocar como qualquer mercadoria, integrando-se às "formas de poder que outrora atacava", como observa Subirats (2001, p. 1 e 26).

A máquina, por substituir a força humana, assumia o papel de liberadora do homem moderno, e por sua eficiência técnica, postulava o aumento da produção industrial, colocando-se como uma espécie de "totem moderno" (emprestando a expressão de Lewis Mumford). Acreditava-se na sua capacidade de impor mudanças na estrutura urbana e social, impulsionar a pesquisa científica e alterar o pensamento e os processos de criação. E se a arte, como já citado, deixava de centrar-se em uma ordem espiritual ou divinal, para inserir-se como meio de expressão, como conhecimento específico e como um bem de mercado, também deixaria de se pautar exclusivamente numa fatura manual. Sem entrar no mérito da polêmica que isso gerou, alguns logo passariam a recorrer a anteparos mecânicos (fotografia), a utilizar-se de materiais industriais e a confiar a execução de determinadas obras aos operários de uma fábrica, como preconizaram os signatários da Bauhaus, no início do século passado. 
Ao vincular-se a praxe artística ao espírito funcionalista da vida moderna, os investimentos adotados, até então, pelos artistas, com o objetivo de imprimir movimento às formas, também iriam ser revistos. Investiam em novos recursos e materiais industriais, buscando a eficiência que os efeitos gráficos e pictóricos adotados com tal finalidade não lhes proporcionavam, por apenas simularem, de maneira fictícia ou ilusória, a ideia de dinamismo. Assim, logo após a invenção da fotografia várias experiências pautadas na simbiose arte/ciência, visavam desmontar a tradicional concepção estática, representativa e retiniana das formas artísticas. O processo mimético ou representativo do mundo objetivo através da arte passava a ser questionado, abrindo espaço à experiência criativa aliada à potência do pensamento científico.

A constatação de que os elementos do mundo não são estáticos, mas dinâmicos, seria confirmada pelos experimentos fotográficos desenvolvidos por Marey e Muybridge, o que contribuiria para modificar os processos de criação até então em vigor e ampliar as pesquisas e investimentos artísticos voltados para a questão do movimento. Depois de instigar a metamorfose da imagem e entrar na disputa pelo estatuto de arte, a fotografia imporia mudanças na maneira de compreender e representar o mundo, mais enfaticamente a partir do impressionismo, quando a "representação imutável das coisas era abalada e relativizada" e sua "aparência passava a ser determinada pelo Tempo, pela Luz e pelo Movimento", observa Bihalji-Merin (1979, p. 60-61).

No início do século XX, com o surgimento das primeiras vanguardas, a "máquina adquire um valor cultural universal" e torna-se "um princípio de homogeneização e de organização social”. Entretanto, no contexto da modernidade, a máquina não deixava de ser objeto de contradição e controvérsia. Para alguns, tornava-se objeto "demiúrgico, profético e messiânico", isto é, "força redentora capaz de pôr fim às guerras, às visões de decadência e às próprias revoluções sociais”, surgidas durante ou em decorrência da I Guerra Mundial; para outros, não passava de instrumento "demoníaco, infernal e destrutivo" (SUBIRATS, 1984, p. 26-31).

Por sua vez, futuristas, construtivistas e dadaístas creditaram à dinâmica da máquina e ao caráter enunciativo do cinema o poder de instaurar uma nova ordem social e produtiva, sintonizados com o frenesi da vida moderna. Para eles, o cinema tornara-se fonte de novas percepções, expressas pela simultaneidade, pelo dinamismo e pela potência reverberante da luz. Por essa razão fascinava a multidão urbana e inspirava a praxe e a reflexão teórica de um número sempre crescente de artistas, que pleiteavam pôr em xeque os postulados perceptivos e visuais do passado.

Ao apresentar pela primeira vez desenhos que confirmavam o seu interesse pela máquina, na revista 291, editada por Stieglitz na cidade de Nova York, em 1915, o dadaísta francês Picabia assim se posicionou em depoimento à imprensa:

Quase imediatamente depois de minha chegada aos Estados Unidos tive a intuição de que o gênio do mundo moderno estava na maquinaria e que por meio dela se encontraria uma forma de expressão das mais vigorosas [...]. A máquina tornou-se mais do que um simples acessório da vida. Ela é, na verdade, parte da vida humana - talvez a própria alma (apud TOMKINS, 2004, p. 190).

Esses e outros fatores contribuíram de diferentes maneiras, para modificar o ideário poético e as propostas criativas, ampliando as pesquisas e investimentos que se propunham desmontar e romper com a representação naturalista e estática das formas e obje- 
tos artísticos. Com tal propósito, seriam levadas às últimas consequências, por cubistas, futuristas, construtivistas, ou mesmo por dadaístas, como Léger, Picabia e Duchamp, em diferentes pesquisas experimentais, extensivas inclusive ao cinema, desenvolvendo, respectivamente, entre 1924 e 1926: Ballet Mécanique, Entr'acte e Anémic Cinéma.

Se tais experiências significavam considerável mudança em relação às propostas artísticas precedentes, também atestavam que esses e outros artistas se conscientizaram de que não seria possível imprimir movimento real às formas artísticas, recorrendo tão somente aos materiais e processos tradicionais da pintura e da escultura, passando a investir, quase que simultaneamente, em variados processos, materiais e recursos eletromecânicos com tal propósito. Entre elas, vale citar as desenvolvidas por Naum Gabo, Marcel Duchamp e Moholy-Nagy, envolvendo projeções luminosas para gerar efeitos dinâmicos e reverberantes no espaço.

Com a ajuda de um engenheiro, Duchamp construiu seu primeiro mecanismo ótico, Placas de vidro rotativas (1923). Apresentou a seguir outra proposta mais sofisticada, denominada Semi-esfera Rotativa (Ótica de Precisão) (1925). Tratava-se de objeto-máquina, que continha um pequeno círculo branco de madeira com uma incisão no meio, em cuja superfície o artista pintou círculos concêntricos pretos. Montado "sobre um disco de cobre, girava impulsionado por um pequeno motor, encerrado em uma redoma de vidro coberta de veludo preto", fazendo com que as linhas das circunferências pintadas "parecessem mover-se para frente e para trás no espaço" (TOMKINS, 2004, p. 281-284).

O húngaro Moholy-Nagy (1895-1946) realizou inusitadas experimentações com fotografia e cinema e prestou, ainda, significativa contribuição teórica aos primórdios da arte cinética, ao anunciar os efeitos do movimento e da luz sobre a percepção, concepção e recepção dos novos objetos culturais. Profetizou a mudança de postura do espectador, postulando que este passaria da posição de contemplador para a de participante ativo da obra de arte, num manifesto lançado em parceria com Alfred Kemeny, em 1922 (BARRET, 1991, p. 153). Esse professor da Bauhaus procurou pôr tais ideias em prática, criando um complexo objeto cinético, o Modulador de Luz-espaço (Light-Space Modulator), concluído em 1930, para emitir efeitos luminosos surpreendentes no cenário de uma ópera. Ao ser acionada mecanicamente, a máquina lançava fachos de luz que tornavam a própria superfície metálica do objeto translúcida e reverberante. A luz transformava-se, assim, em matéria escultural e mantinha implícita a ideia de ritmo dinâmico e de princípio de dissolução da forma, além de pôr em xeque ou em crise a velha questão da resistência e perenidade dos materiais.

Esses e outros inventos cinéticos de autoria de Moholy-Nagy foram contemporâneos às experiências do americano Alexander Calder, que culminaram com a criação dos primeiros móbiles movidos por motores ocultos na base dos objetos, e substituídos depois por uma fonte natural de energia: corrente de ar ou de vento, ou que se movimentavam por um simples toque do espectador (1932).

Esses inventos experimentais acabariam se tornando a base de formulação da arte cinética, que, no entanto, iria se instituir como vertente artística, apenas na metade da década de 1950, em decorrência, principalmente, do aumento da produção e da disponibilidade de materiais industriais e de pesquisas tecnológicas, após o término da II Guerra Mundial. Foi quando a produção de objetos/esculturais/máquinas dotados de movimento eletromecânico ou eletromagnético se tornou possível, aparecia de maneira quase concomitante em países mais ou menos desenvolvidos, com destaque para a França, Estados Unidos e Brasil. Por meio de soluções criativas, ma- 
teriais, técnicas e efeitos plásticos muito diversificados, artistas como Yaacov Agam, Pol Bury, Alexander Calder, Jean Tinguely, Kramer, Frank Malina, Nicolas Schöffer, Von Graevenitz, Takis, Davide Boriani, Abraham Palatnik, Mary Vieira e Maurício Salgueiro criaram obras dinâmicas, que exigiam conhecimentos em engenharia ou em algum domínio técnico no campo da mecânica e da eletricidade. Aqueles que não dispunham de tais conhecimentos uniram-se a engenheiros ou a técnicos especializados que obter os resultados desejados em seus respectivos projetos.

O atraso tecnológico, a incipiente tecnologia disponível, os altos custos dos investimentos e a inexistência de um mercado para esse gênero de obras, não impediu que aqueles artistas brasileiros ou de outros países da América Latina desenvolvessem experiências cinéticas pioneiras, a exemplo dos argentinos Gyula Kosice e Julio Le Parc e dos venezuelanos Jésus Raphael Soto e Carlos Cruz-Diez. A maioria deles, inicialmente, tirou partido dos efeitos óticos e dinâmicos de linhas e formas geométricas, como decorrência natural da praxe concretista por eles professada. Em contato com exposições de obras cinéticas durante a permanência que mantiveram, de modo especial em Paris, imprimiriam novos rumos a seus projetos criativos.

No caso específico de Palatnik e Vieira a produção de obras dotadas de movimento teve início no país no final da década de 1940, respectivamente em efetivo diálogo com a pintura e com a escultura concretista. O primeiro criou objetos/caixas, nas quais se alojavam fontes luminosas (lâmpadas coloridas) e um pequeno cilindro pintado. Ao serem impulsionados por um pequeno motor elétrico (que o artista aprendeu a montar durante estudos em Israel), a luz produzia efeitos dinâmicos sobre a superfície/écran transparente de uma das faces da caixa, lembrando pinturas abstratas. Tal como no cinema, para que a ação performática da caixa voltasse a se repetir, bastava que o público interativo acionasse um pequeno interruptor. Mary Vieira, por sua vez, assumia outra direção, criando esculturas de metal, que rodopiavam no espaço, seja com o auxílio de um pequeno motor, seja pela ação do público disposto a interagir e a mover uma sequência de lâminas de metal, fixadas a um eixo central.

Embora ambos obtivessem imediato reconhecimento no exterior, apenas muito recentemente é que o legado cinético desses e de outros artistas passou a merecer alguma atenção dos estudiosos e das instituições culturais brasileiras, e a participar mais frequentemente de exposições. Para justificar a indiferença e mesmo o desconhecimento que paira, de modo especial sobre as obras cinéticas de Mary Vieira, é comum se afirmar que ela as produziu na Europa, para onde se transferiu em 1952. Todavia, se a argumentação não é de todo verdadeira, considerando que as primeiras obras dotadas de movimento foram executadas por ela ainda no Brasil, a matriz de grande parte das obras que ela executou na Europa foram pequenas maquetes ou protótipos concebidos aqui, mas levados por ela quando se mudou para lá, como veremos adiante.

Na década de 1960, número um pouco mais dilatado de artistas passaria a investir na produção de obras dinâmicas, ampliando o leque de pesquisas e criações envolvendo arte e tecnologia. Entre eles o supracitado capixaba radicado no Rio de Janeiro, Maurício Salgueiro (1930), o cearense (com longa permanência em Paris) Sérvulo Esmeraldo (1929), o italiano residente na capital paulista, Danilo Di Prete (1911-1985) e o japonês Yutaka Toyota (1931), nomes que apenas recentemente tiveram sua obra revitalizada e retirada do esquecimento.

Dada a impossibilidade de refletir neste artigo sobre a produção de todos os artistas citados, optou-se por discorrer, mesmo que de maneira conscientemente 
parcial, sobre a especificidade da escultura cinética de Mary Vieira. Primeiro, por ter realizado as primeiras obras cinéticas em Minas Gerais, onde também se deu a sua formação, e por comemorar-se este ano os sessenta anos da ida da artista para a Suíça, lá atuando até à morte em 2001. Segundo, por ter sido também ela a primeira artista brasileira a produzir obras cinéticas de grandes dimensões, para serem instaladas em espaços públicos no Brasil e no exterior. Além disso, sua obra, como já citado, é quase desconhecida e pouco estudada no país de origem, embora a artista tivesse participado de algumas edições da Bienal de São Paulo e realizado mostras individuais em diferentes instituições culturais brasileiras, durante o longo período vivido na Europa.

\section{O investimento isolado de Mary Vieira}

Nascida no interior de São Paulo, mas criada no Sul de Minas Gerais, Mary Vieira (1927-2001) tornava-se uma das pioneiras da arte cinética no Brasil e no mundo, ao construir, ainda na segunda metade da década de 1940, as primeiras esculturas dinâmicas, denominadas Polivolumes. Tal fenômeno se torna ainda mais marcante, considerando que isso ocorreu pouco depois da jovem iniciar a produção de desenhos, pinturas e esculturas abstratas, de formulação geométrica, fora do eixo hegemônico. A praxe desenvolvida por Mary Vieira também ratifica a afirmação de Ronaldo Brito, de que foi o concretismo que desvendou aos artistas o encontro com a "recém-criada autonomia" e o desvendamento de "um método de produção artística que reuniu manipulação, inventiva das formas e equacionamento rigoroso", no esforço de retirar a arte "do terreno do puro intuicionismo" (BRITO, 1985, p. 37-39).

E também não deixa de ser curioso o fato de Mary Vieira iniciar a sua trajetória criativa pela tendência construtiva, antes mesmo que as premissas da abstração tivessem sido formuladas e alcançassem maior difusão no nosso país. Opunha-se, assim, à representação figurativa, em que se pautava a maioria dos artistas brasileiros, ainda naquele momento. Antecipou-se, portanto, às premissas que seriam preconizadas, anos depois, pelos membros dos grupos Ruptura e Frente, respectivamente na capital paulista e no Rio de Janeiro, no início dos anos 1950. Convicta do projeto poético que se propunha desenvolver, a artista procuraria consolidar e dar maior consistência a sua linguagem concreta, ao optar seguir para a Europa, para beber diretamente na fonte onde foi formulada essa tendência.

Nesse sentido, parece-nos pertinente indagar: a que atribuir o interesse inusitado dessa jovem criada no interior de Minas Gerais? Segundo costumava afirmar a própria artista, muito precocemente demonstrou preferência por se expressar através de elementos geométricos, por lhe parecerem mais pertinentes à solução de determinadas questões espaciais, do que as formas representativas ou figurais. Estaria, então, a música e o teatro no cerne do despertar precoce de Mary Vieira pela experimentação espacial e pensamento abstrato? Sem a intenção de encontrar resposta para a questão, vale destacar que essa filha de abastados proprietários rurais e amantes da arte, teve contato, desde a infância, com diferentes manifestações artísticas e culturais. Algumas dessas manifestações eram promovidas pelos próprios familiares, que chegaram, inclusive, a constituir e manter uma pequena orquestra, que se apresentava na região de Alfenas, no sul de Minas Gerais. A residência paterna da jovem era também frequentada por notáveis pintores, músicos e escritores. 
E se ainda muito jovem Vieira teve contato com as telas de Segall, Anita, Tarsila, Portinari, Di Cavalcanti - numa época em que a pintura figurativa de caráter social dominava a cena brasileira -, ao contrário do que se poderia esperar, ao decidir seguir a carreira artística, a jovem transferiu-se para a capital mineira, frequentando o recém-criado Instituto de Belas Artes, do Parque Municipal, idealizado pelo então Prefeito, Juscelino Kubitschek de Oliveira, tornando-se aluna de desenho e pintura de Guignard, em 1944. Embora esse artista-professor, logo constatasse que o processo expressivo da aluna não coincidia com o seu não iria tolher a liberdade criativa ou interferir nos exercícios de desenho e pintura, ao constatar que em seus exercícios ela iria refutar as deformações expressionistas, equacionados por outros pintores que the eram familiares.

Em depoimento concedido anos mais tarde, Mary Vieira afirmara que Guignard foi seu único e verdadeiro mestre, e o grande incentivador, primeiro, por não ter pretendido Ihe "ensinar nada", e segundo, por "estimulá-la a prosseguir", sem persuadi-la a mudar ou redirecionar o foco de sua opção criativa, além de tê-la ajudado a equacionar melhor os problemas de espaço (apud COUTINHO, 1988).

Se como se depreende nesse e em outros depoimentos, a questão espacial foi fator determinante para Mary Vieira, também parece ter sido determinante para que, desde o início de sua trajetória artística, optasse por expressar-se por meio de composições geométricas, e não pela figuração. Anos mais tarde afirmava em entrevista, que embora acalentasse profunda admiração e respeito por inúmeros expoentes da pintura figurativa, para ela "arte sempre significou a possibilidade de fazer algo além da natureza" (apud ARAÚJO, 1979, p. 118).

Curiosa e inquieta, com a chegada de Franz Weissmann ao Instituto de Belas Artes, a estudante de arte logo passaria a frequentar as aulas de modelagem e de escultura ministradas pelo mestre, decidindo abandonar a pintura pelas formas tridimensionais. Tornava-se colega de Amilcar de Castro, com quem iria partilhar os anseios em torno das experiências concretistas e a vontade manifesta de atribuir movimento às formas.

Passava a elaborar, com grande desenvoltura e senso de equilíbrio, pequenas maquetes e projetos de futuras obras tridimensionais, pautadas pela síntese formal em exímias composições geométricas, que irrompiam no espaço e pareciam tributárias de Arp e Brancusi, que não passariam indiferentes ao mestre. Embora nessa época Weisssmann ainda elaborasse esculturas figurativas, respeitou a determinação construtiva da aluna, sem interferir no seu processo criativo, pois como afirmaria anos depois, logo percebeu ter diante de si uma "escultora nata". ${ }^{2}$

Fora do âmbito daquela instituição o ineditismo da obra escultórica da jovem Mary Vieira seria visto com estranhamento e indiferença, o que não a demoveu de prosseguir no rumo da arte concreta. Com convicção e perseverança investia na continuidade desse projeto criativo, mesmo que se ressentisse do isolamento, e principalmente da dificuldade de interlocução com outros artistas. Na maturidade parece

\footnotetext{
2 Formado pela Escola Nacional de Belas Artes, esse professor e escultor elaborava, então, no ateliê que instalou na capital mineira, esculturas de figuras humanas alongadas e sintéticas, nas quais explorava a contraposição entre cheios e vazios, numa referência a Henry Moore e Alberto Giacometti. A produção de obras concretas, por parte de Weissmann teve início na década de 1950, o mesmo ocorrendo com seu colega Amílcar de Castro. E embora eles não chegassem a produzir obras cinéticas, Mary Vieira observaria que esses dois escultores pleitearam atribuir a suas obras, através de alguns artifícios, um movimento virtual.
} 
ter mudado de posição, ao destacar que o isolamento é necessário ao processo de transformação, à investigação e à busca da verdade, por todo "aquele que deseja criar e não apenas brincar com arte" (apud TAVARES, 1980).

Essa incansável e compulsiva pesquisadora de formas, meios e materiais, iria se defrontar, pouco depois de concluir os estudos, com o desafio de imprimir às formas abstratas um movimento real. Com tal objetivo, executou alguns protótipos e iniciou a investigação de soluções para movimentar as obras, no ateliê que instalou em Sabará (1947), na antiga capela de Nossa Senhora do Ó, então fechada ao culto. E para a elaboração das primeiras esculturas cinéticas em metal, Mary Vieira recorreu às oficinas da CSBM (Companhia Siderúrgica Belgo Mineira), empresa que possuía, então, as mais modernas instalações industriais do país.

Ali foram executadas entre outras: Formas Espirálicas, Eletro-rotativas de Perfuração Virtual (1948), medindo seis metros de altura, acionada por um motor elétrico, a qual foi enviada à Exposição Nacional das Classes Produtoras Brasileiras, realizada em Araxá (MG), no mesmo ano. Considerada pela crítica internacional como a primeira escultura cinética monumental e interativa realizada no mundo, ao término do evento a obra foi instalada no espaço externo do Grande Hotel, naquela cidade. A empresa Belgo Mineira adquiriu, na mesma ocasião, à artista, algumas das esculturas executadas em suas oficinas para a sua sede em Araxá.

Se na época a arte abstrata não era ainda compreendida e assimilada no país, bem se pode imaginar o estranhamento e a perplexidade que teriam causado aos interlocutores e à crítica mineira, as primeiras esculturas dinâmicas de autoria de Mary Vieira. Basta considerar que até a transferência da artista para a Europa (1952), a crítica brasileira não se pronunciou a respeito desse gênero de obras por ela produzidas. Indagada sobre o processo de intermediação entre arte, ciência e tecnologia, a artista iria afirmar não revelar apreço pelas teorias racionalistas ou por conceitos matemáticos. Atribuía a eficiência e a precisão incondicional de suas obras a uma "indispensável disciplina e liberdade de criação" e ao "aprofundamento da consciência pela observação e o pensamento" (VIEIRA, 1976). E parece ter sido a perseverança que Ihe facultou atualizar e diversificar as possibilidades expressivas e cognitivas, calculando e plasmando com coerência e maestria esculturas cinética, denominadas genericamente pela autora de Polivolumes, sem se desviar jamais da poética construtiva. 

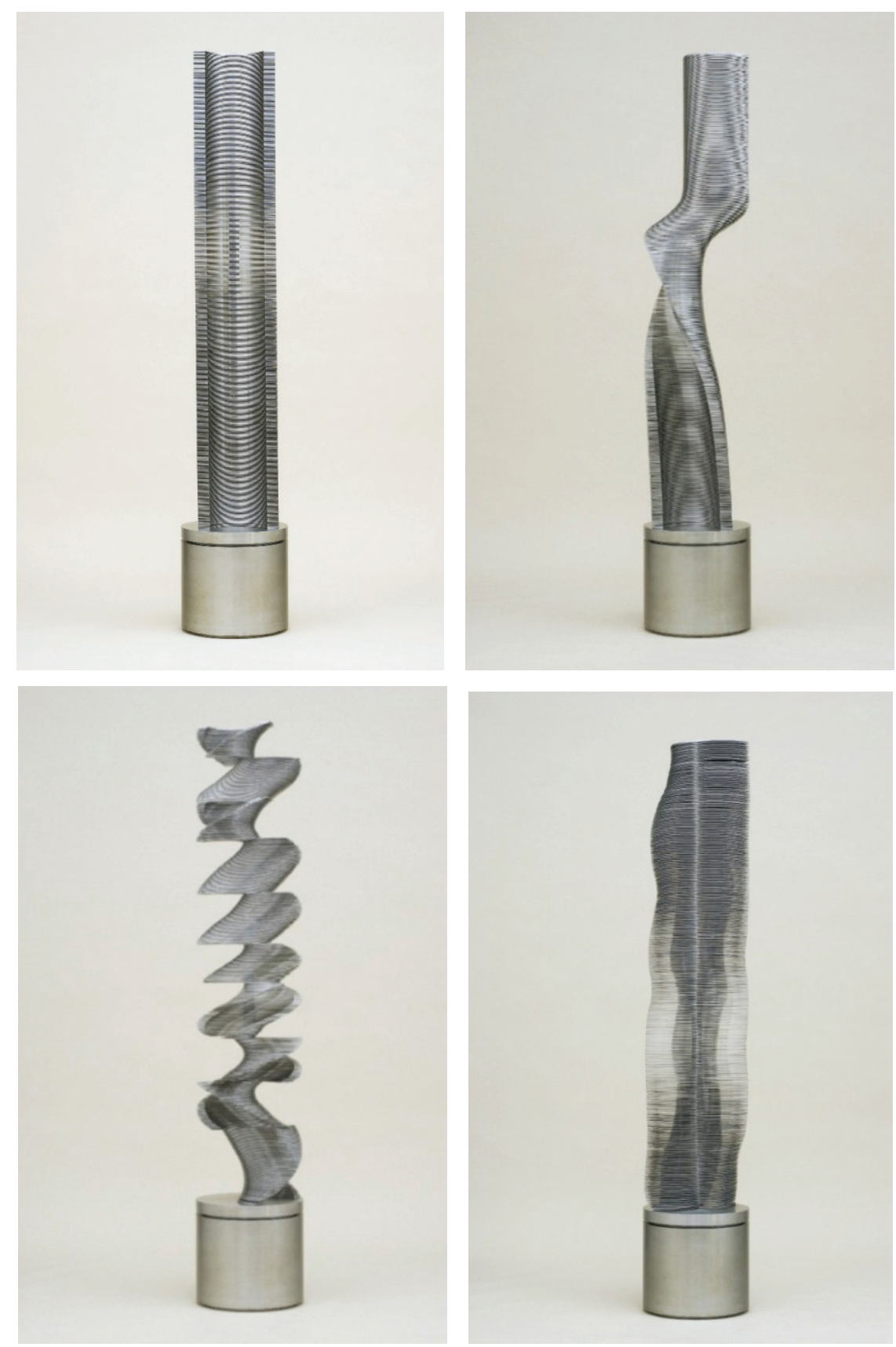

Figuras 1 a 4 - Mary Vieira, Circuito Elipsoidal Côncavo e Convexo no 1 (Interações em quatro tempos), alumínio anodizado. Acervo Museu de Arte Brasileira da FAAP. Fonte: Fotografia do Acervo FAAP (Autor ignorado).

Para obter os investimentos necessários à pesquisa e concretização desse gênero de obras, Mary Vieira executou ainda no final da década de 1940, projeto de arquitetura e ambientação na boate do Cassino Palace, em Poços de Caldas e por encomenda do Prefeito Miguel de Carvalho Dias, produziu, ainda, para as termas estaduais de Poços de Caldas um polivolume de solução dinâmico-espacial. Para a cidade de Lambari 
(MG), além de trabalhos de programação visual, ${ }^{3}$ executou alguns polivolumes ludo-táteis, entre eles o Circuito Elipsoidal Côncavo e Convexo no 1, (acima reproduzido), hoje no acervo do Museu de Arte Brasileira da FAAP (SP), entre outros que acabaram se dispersando. Esses sólidos cilíndricos, constituídos por uma sequência de lâminas fixadas num eixo central, ganhariam novas versões e dimensões na década de 1960. Acionados um meio eletromecânico, empreendem no espaço, e por um tempo programado, um movimento de rotação helicoidal, cuja ação faz com que a matéria de que são constituídos pareça entrar em dissolvência ou desintegração, apresentando-se à visão como uma sobreposição de planos instáveis, inapreensíveis ou movediços.

No Rio de Janeiro, a artista aceitaria o desafio de elaborar um projeto inovador de programação visual para o Hotel Quitandinha. E durante o período em que permaneceu em Petrópolis (final dos anos 1940), a artista executou vários projetos escultóricos no ateliê que lá instalou. A artista não diferenciava assim, os projetos de sua funcional ou prático dos processos artísticos, recorrendo aos mesmos princípios formais, isto é ao emprego da geometria na estruturação do espaço-tempo. Confirmaria tais premissas ao afirmar inúmeras vezes "que a forma nada mais é do que um movimento no tempo" (VIEIRA, depoimento a Gândara, 1978, p. 18). Assim, antes ainda de se transferir para a Europa, Mary Vieira elaborou os desenhos da primeira fase de uma sequência litográfica denominada Tempos de um Movimento. A série seria editada logo depois de sua chegada à Europa em dois volumes, pela Casa Spiral Press, de Berna (Suíça), em 1953, por incentivo e com a colaboração de Max Bill.

A aproximação da brasileira e do suíço ocorreu durante a exposição realizada por Max Bill, no Museu de Arte de São Paulo (1950) e da participação e premiação na I Bienal (1951). O impacto causado pelas obras concretistas de Bill revestiu-se de entusiasmo e identificação, segundo a própria Mary Vieira, que, ao adentrar a exposição na companhia da pintora Maria Leontina teria desabafado a esta: "Há gente no mundo procurando e fazendo o que eu também procuro e penso. Não estou mais sozinha. Se aqui não me compreendem, vou trabalhar na Europa, pois quero e preciso descobrir a origem da forma" (VIEIRA apud PONTUAL, 1976).

Se o projeto criativo de Max Bill permitiu à brasileira compreender a verdadeira acepção de nosso atraso artístico, também foi determinante para que ela decidisse se transferir para a Suíça (1952), tornando-se aluna daquele artista. Ao levar com ela as pequenas maquetes das esculturas que se propunha elaborar, confirmava a obstinação de ali dar prosseguimento à rota precocemente definida por ela. Assim, não iria alterar ou se desviar do projeto programático de sua linguagem escultórica, afirmando, anos depois, que os protótipos levados daqui para lá foram transformados por ela em obras monumentais, instaladas em várias cidades europeias, brasileiras e norte-americanas. Segundo a artista, ao olhar atentamente aquelas maquetes certificou-se que não Ihe interessava "criar uma forma atrás da outra, mas (queria) encontrar o ponto de origem de toda a forma" e o "movimento contínuo, que aspira ao infinito" (apud TAVARES, 1980).

\footnotetext{
A partir dessa época, em paralelo às obras escultóricas Mary Vieira iria desenvolver, no Brasil e no exterior, inúmeras obras de design gráfico, atividade que também foi exercida por vários outros concretistas e neoconcretistas brasileiros, a exemplo de Amílcar de Castro, Geraldo de Barros, Alexandre Wollner, Almir Mavignier, Ligia Pape. Deixamos de abordar esse gênero de produção, por fugir do foco deste artigo. Vale ressaltar, no entanto, que nos cartazes e projetos visuais criados para divulgar feiras industriais, realizadas em estâncias hidrominerais, do circuito das águas mineiro, e exposições de arte brasileira em instituições culturais européias, a artista se manteve fiel aos princípios concretistas, buscando um processo de comunicação eficiente, economizando no emprego de elementos formais e nas cores chapadas.
} 
$\mathrm{Na}$ verdade, além da vontade de dar prosseguimento ao projeto iniciado no Brasil, almejava ser aceita e compreendida, encontrando em Max Bill (1908-1994) seu principal interlocutor e generoso incentivador, acolhendo-a logo no respeitado grupo concreto Allianz (Zurique), por ele liderado. Isso não apenas facultou a rápida inserção de Mary Vieira no meio artístico europeu, como permitiu a sua participação em exposições realizadas por esse grupo concretista, que além de Bill era integrado por uma plêiade de artistas do porte de Richard Lhose, Leo Leupi, Walter Bodmaer, Camille Graesser e Verena Loewnsberg, os quais fundamentavam as respectivas produções em cálculos matemáticos, recorrendo a uma gramática considerada universal, constituída por formas geométricas.

Na Europa a brasileira iria se aproximar, também, de escultores que admirava e com os quais se identificava esteticamente, desde o início da carreira artística: Brancusi, Arp, Vantongerloo, Pevsner, Gabo, Lipchitz, além do teórico alemão Max Bense. Dessa maneira, evidencia-se nos polivolumes criados por ela em Minas Gerais, um possível diálogo com obras como: Construção Cinética (1920), de autoria de Naum Gabo, Pássaro no Espaço (1928) e Coluna sem fim (1938), de Brancusi.

E ainda que Mary Vieira afirmasse desconhecer a obra cinética de Pevsner e Gabo, antes de se instalar na Europa, sabe-se que sempre se manteve atenta à produção artística internacional, além de enfatizar, em depoimentos, a significativa contribuição dos latino-americanos à arte construtiva. Entre os brasileiros, afirmaria alguns anos depois, considerar-se tributária de conterrâneos como Amílcar de Castro e Lygia Clark, incluindo, ainda, na sua lista de preferências Franz Weissmann, Abraham Palatnik, Almir Mavignier e Sérgio Camargo.

Salvaguardadas as devidas concepções plásticas e temporais, de modo especial no que concerne às diminutas proporções e efeitos visuais obtidos por Mary Vieira em seus polivolumes cinéticos seminais, as Rotogravuras de autoria de Marcel Duchamp, parecem ter sido sua fonte de inspiração e diálogo. Esse prognóstico parece evidenciar-se, ainda, seja nas formas espiraladas dos polivolumes, seja nos círculos concêntricos recortados em alumínio ou acrílico, que se movem em torno de um eixo central, acionados por um mecanismo elétrico, tal como ocorre em Disco Plástico, Ideia para uma Progressão Serial (1953-1962), pertencente à coleção do Museu de Arte Contemporânea da USP. O movimento empreendido pelas linhas e planos, provoca no interlocutor a sensação de visualizar efeitos côncavos e convexos, num incessante jogo de relações virtuais e de articulação de sentidos inesgotável.

Na década de 1950, algumas esculturas cinéticas produzidas pela brasileira patenteavam o seu empenho em promover a interação entre espaço, luz, tempo e movimento. A especificidade e o título atribuído a um de seus polivolumes: Luz-Espaço: Tempo em Movimento (1953-5), hoje pertencente ao MAM-SP, parece confirmar tal assertiva. Entretanto, mesmo não mantendo similaridade formal, funcional ou estrutural, essa obra não deixa de remeter, de alguma maneira, ao Modelador de Luz e Espaço (1923-30), de autoria de Moholy-Nagy.

A ousadia criativa e a simplicidade funcional das propostas cinéticas elaboradas pela nossa artista nas décadas de 1950 e 1960 não deixam de confirmar-se, principalmente, se comparadas, a objetos criados na mesma época, por outros congêneres brasileiros e estrangeiros, a exemplo de Jean Tinguely, Abraham Palatnik e Maurício Salgueiro. Embora de funcionamento preciso e fascinante, as engenhocas produzidas por esses e por outros artistas utilizam na sua construção uma paraferná- 
lia perdulária de fios, lâmpadas, motores e outros materiais. E mesmo que em alguns casos esses materiais viscerais permanecessem ocultos no interior dos objetos, estes assumem uma aparência estranha ou mesmo caótica, lembrando geringonças mecânicas, máquinas irônicas ou assustadoras.

Em contrapartida, as cinéticas de autoria de Mary Vieira, balizam-se por absoluta economia, precisão e justeza de meios e materiais, objetividade e equilíbrio. Pautando-se da ideia de síntese e possuidoras de volumetrias lisas e assépticas, tanto as obras de pequenas como as de grandes dimensões, não deixam de remeter às esculturas minimalistas de Robert Morris, Carl Andre ou Donald Judd. De configuração cilíndrica ou prismática, as formas escultóricas em metal ou mármore polido, eram elaboradas por empresas especializadas, a partir de pequenos protótipos e com a supervisão da autora. Mesmo possuindo proporções e pesos variados, não apresentam diferença significativa no que se refere a funcionamento, nem grande variação nos módulos formais. Assim, mesmo os polivolumes elaborados com avantajadas dimensões e considerável peso das respectivas estruturas metálicas, ao se movimentarem em rodopio no espaço, esbanjam elegância, leveza e volúpia.

As obras de pequenas dimensões movimentam-se, na maioria das vezes, por meio de mecanismos eletromecânicos, a exemplo de Momento (década de 1970). A rotação do corpo cilíndrico em torno de si mesmo dá a sensação de deformar, fragmentar, facetar e multiplicar a matéria sólida, gerando planos diáfanos, que neutralizam o volume, a densidade e o peso da matéria de que se constitui.

Nas obras monumentais construídas para espaços públicos, em aço cromado, aço inoxidável, mármore, alumínio, concreto, madeira, ou hibridizando diferentes materiais, foi necessário que a artista engendrasse outras maneiras de o público interagir com elas, com o intuito de movimentá-las e modificá-las. Essas soluções decorreram, tanto em virtude dos altos investimentos que seriam necessários para manter em funcionamento contínuo os mecanismos eletromecânicos, quanto para a integridade das obras. Por essa razão, a artista não recorreu a motores, mas a lâminas flexíveis de metal, que podem ser movidas e reordenadas, manualmente, pelo público interativo, para gerar variadas configurações visuais.

Para isso, Vieira seccionava as formas cilíndricas das esculturas em duas partes, inserindo as lâminas paralelas de aço inoxidável, em um eixo vertical, que interliga os blocos seccionados. Segundo a vontade formadora do público, esse intervalo ou interconexão entre as duas partes do sólido, podia assumir, entre outras configurações, a de uma coluna espiralada ou helicoidal, quebrando a regularidade e a lisura formal da escultura, para assemelhar-se a colunas barrocas. A sinuosidade empreendida pelo reposicionamento das lâminas flexíveis atribui aos polivolumes um contorcionismo voluptuoso ou a sensualidade de um corpo dançante, como em: Coluna Centrípeta: Ritmo 2 Rotatório (1954), Ponto de Encontro (1970) e Conexão Livre (1979), ambas com seu corpo cilíndrico construído em alumínio, cada uma delas com vários metros de altura, instaladas respectivamente em Brasília e São Paulo. ${ }^{4}$

\footnotetext{
${ }_{4}$ As duas primeiras obras foram encomendadas à artista por Oscar Niemeyer. Uma delas para ser integrada à Praça dos Três Poderes a outra destinada ao saguão do edifício do Ministério das Relações Exteriores (Itamarati), em Brasília, projetado por Sérgio Bernardes. A terceira escultura foi instalada no Parque do lbirapuera, na confluência da Avenida 23 de Maio e Pedro Álvares Cabral. Executada em alumínio, pesa cerca de 230 quilos e mede 5 metros de altura por 22 metros de diâmetro territorial. Possui na parte inferior uma sucessão de placas móveis de aço que permitem que o público as movimente de diversas maneiras.
} 


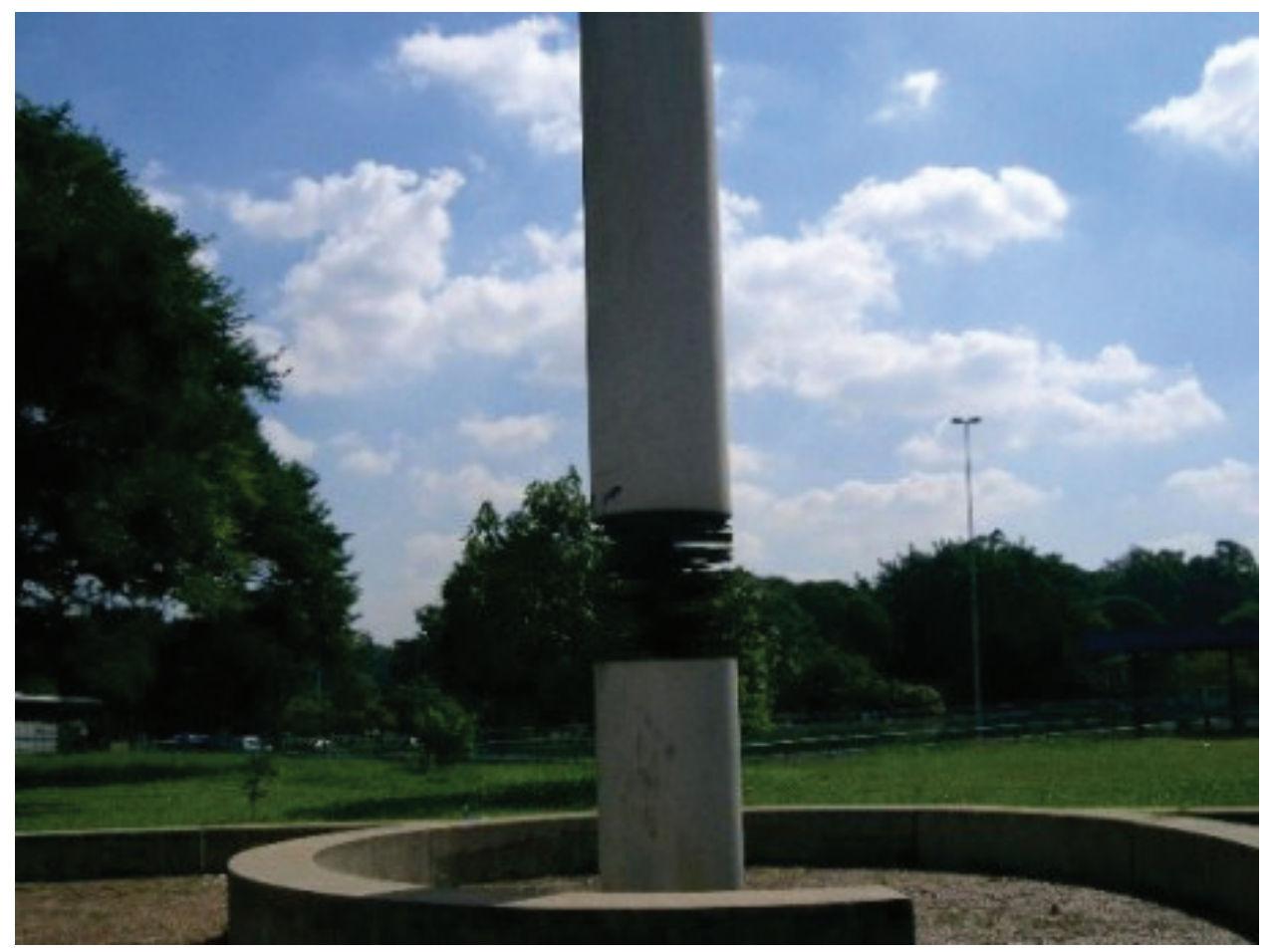

Figura 5 - Mary Vieira, Ponto de Encontro, 1970, alumínio anodizado e concreto. Monumento Público, Parque do Ibirapuera, SP. Fonte: Fotografia da Autora.

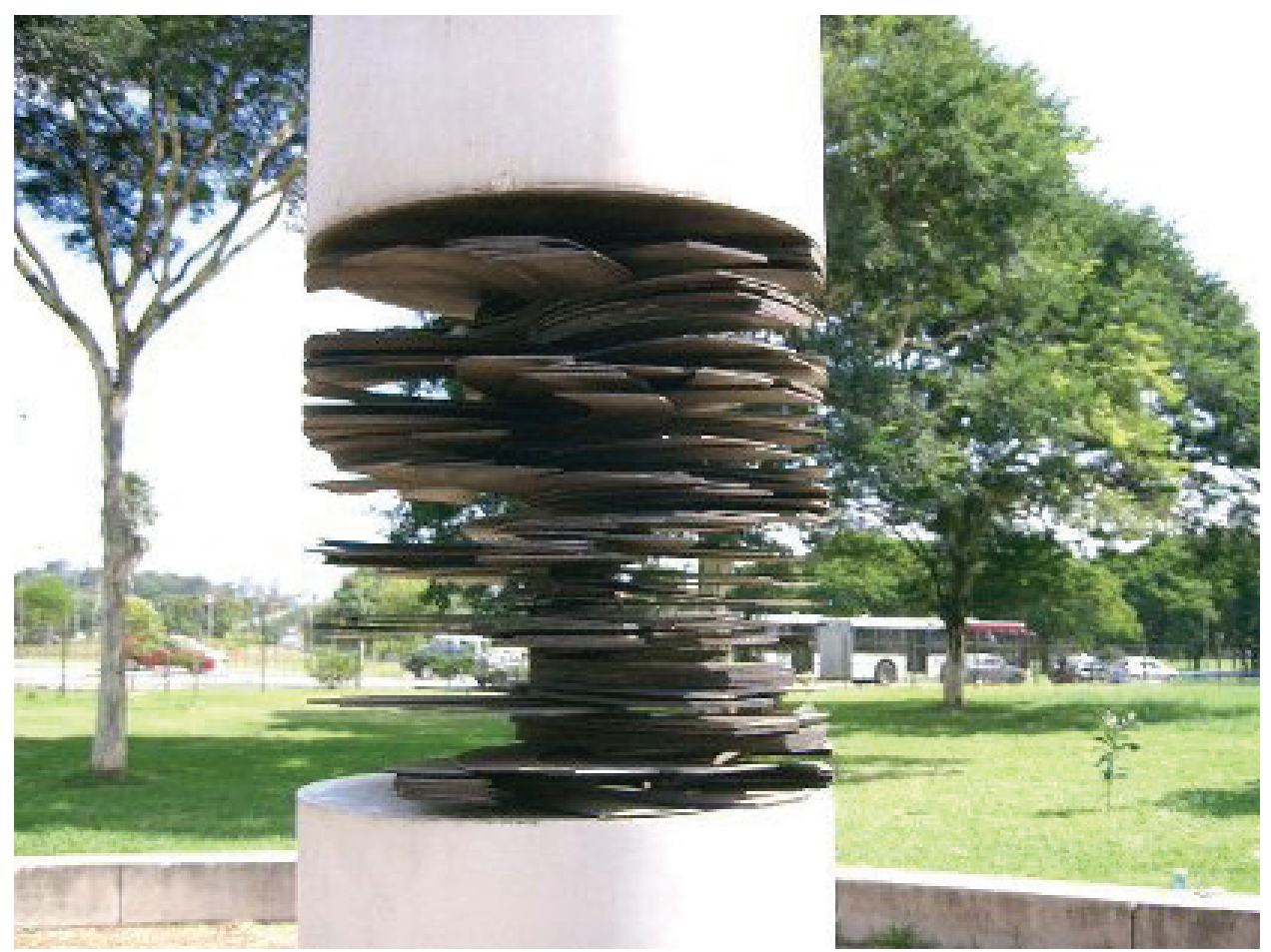

Figura 6 - Mary Vieira, Ponto de Encontro 1970 (pormenor das lâminas flexíveis). Parque do lbirapuera (SP). Fonte: Fotografia da autora. 
E mesmo que Vieira elaborasse esculturas de formas puras e de absoluta precisão, costumava afirmar que procurava atribuir-lhes uma "espiritualidade brasileira". Se tal atributo não deixava de ser paradoxal, a artista parecia estabelecer assim algum tipo de relação entre seus próprios Polivolumes e os Bichos, de Lygia Clark, que pela manipulação e interação do público se modificavam e se transformavam incessantemente, dirimindo a racionalidade, a rigidez e frieza das formas concretas.

\section{Considerações finais}

Com perspicácia e engenhosidade Mary Vieira aspirava imprimir às formas concretistas de suas esculturas cinéticas o que ela chamou de "espiritualidade brasileira", que têm no toque, na gestualidade e na volúpia do movimento dançante, alguns de seus mais marcantes atributos. A energia do movimento em rodopio no espaço, ao atingir a plenitude, torna dissolvente e translúcida a matéria densa de que é feito o corpo da obra, fazendo-o reverberar, adquirir leveza e liberdade, peculiaridades que a artista perseguiu e redimensionou ao longo de sua atividade criativa. Se o movimento parece quebrar a opacidade e a estabilidade dos volumes geométricos, a elegância e a força contorcista desses corpos escultóricos a rodopiar no espaço, dota-os de uma energia vital, que parece expandir-se do interior para o exterior, contagiando o espaço à sua volta. O movimento das formas configura-se, assim, como gesto libertador: desdobra-se e entrecruza-se numa montagem de tempos fragmentários, que se repetem em um eterno recomeçar. Tal como observa Gil (2005, p. 15), "todas as formas do movimento se esboçam antes de se desdobrarem e apresentam movimento antes do movimento".

A vertigem do movimento não traduz apenas a oposição ao caráter estático da escultura convencional, mas encontra seu pé de apoio na dinâmica natural da vida, no transcurso inexorável do tempo, na espontaneidade e singularidade dos gestos, na energia dos movimentos sincronizados de uma dança. Ao criar esculturas modificáveis ou interativas, a brasileira propugnou a criação de diferentes possibilidades rítmicas e rearranjos formais, sem se desviar da relação estrita com a precisão da geometria e o rigor da tecnologia, às quais aliou uma função social. Entendida por esse viés, a linguagem artística de Mary Vieira embora conscientemente universal, mantém no agenciamento entre o tocar, o mover, o modificar, o transformar, o manipular e o fruir a obra ativamente, por meio da ação participativa do público, o vínculo com a "afetividade" e a "espiritualidade" da gente brasileira, a que tantas vezes se referiu Mary Vieira:

Os problemas de pesquisas de ideação estética, sendo universais, não possuem fronteiras geográficas. $O$ real operador plástico possui uma linguagem internacional. A característica da própria origem nacional ou territorial se revela muito mais na escolha da linguagem do que na modalidade de comunicação. Considero-me uma artista de problemática internacional, mas de espiritualidade brasileira, o que poderá ser lido em minha obra, se analisada cuidadosamente (VIEIRA, 1976).

Se a preocupação em promover a integração e a participação social, pautou as propostas de outros artistas cinéticos brasileiros e europeus, tornava-se a principal aspiração de Mary Vieira, antes mesmo de deixar o país. Numa época em que a 
"estética participacionista" (emprestando a expressão de Frank Popper) constituía-se ainda em novidade no campo das artes visuais, a artista afirmava que suas obras não suportavam o espaço sacralizado e o confinamento dos museus, preferindo vê-las instaladas ao ar livre: em jardins, edifícios públicos, indústrias, escolas. Admitia ser essa a única possibilidade da obra oferecer-se, generosamente, à participação espontânea de iniciados ou não, que no ato de interagirem com ela modificam-na e lhe atribuem novos significados.

Sem se desvincular da ideologia e da retórica propugnada pelos concretistas, o contato com os postulantes do grupo suíço potencializou o anseio da escultora de transformar essa gramática aparentemente racional e fria, numa arte de caráter social:

[...] os polivolumes envolvem uma arte social para uma sociedade sem ilusões coletivas; uma forma capaz de suscitar formas individuais; um ludo tátil para um evento visível e multiformal. Os polivolumes inauguram o conceito de arte social no quadro da participação direta do público na co-formação da obra de arte. Antes que os polivolumes pedissem ao espectador para agir pessoalmente sobre o evento formal, a escultura era monoformal, univolumétrica e pedia participação passiva à sua mensagem de beleza hedonística, áulica. Com a possibilidade de contínua renovação formal e espacial que a obra de arte oferece, o espectador torna-se protagonista ativo do espetáculo plástico e a própria escultura se transforma em evento de alcançada sociabilidade lingüística (VIEIRA apud AULER, 1977). ${ }^{5}$

A artista procurou soluções inéditas, mas ao mesmo tempo inalcançáveis, pois iria debater-se ao longo de décadas com a problemática do dinamismo das formas, questão que desde muito precocemente iria instigá-la. Essa aspiração levou-a a almejar para cada obra um gênero diferenciado de movimento, procedimento que parece encontrar correspondência na individualidade da vertigem empreendida pelo corpo de cada bailarino, no ato de deslizar e flutuar livre no espaço.

O conceito de neobarroco, propugnado por Omar Calabrese, parece estabelecer simetria com o contorcionismo, a instabilidade, a metamorfose das formas, o ritmo labiríntico e o movimento ascendente empreendido pelas esculturas cinéticas de Mary Vieira, repetindo-se e se projetando infinitamente num tempo e numa espacialidade abstrata, em efetivo diálogo com a paisagem que as rodeia. É também por meio do movimento que a obra introduz uma abrupta quebra da ordenação e do equilíbrio equalizador do tempo, "em troca da instabilidade, da polidimensionalidade e da mutabilidade" que a vertigem do dinamismo impõe ao espaço circundante. A volúpia do rodopio e a compulsão pelo monumental tem a nítida intenção de quebrar a monotonia e a rigidez da matéria e dos sólidos volumétricos, o conceito de homogeneização, repetição e equalização pela geometria, o que segundo o teórico

\footnotetext{
5 Foi com essa mesma intenção social que a artista facultou à Casa A. Furst, de Berlim, em 1955, a edição de série experimental de duzentos exemplares de uma de suas esculturas, que explorava o dinamismo óptico-visual, denominada Luz-Espaço: tempo em movimento, a partir de um protótipo. A rede de lojas Globus, de Zurique, editou em 1965 uma série de cinco mil exemplares do polivolume Disco Plástico (1953-1960), cujo protótipo foi incorporado à coleção do MAC/USP. Entretanto, a Casa Spiral Press, de Berna já havia editado, em 1953, um álbum de litografias, elaboradas a partir de uma série de desenhos e guaches, produzidos no ano anterior por Mary Vieira, na qual tratava de problemas cinético-virtuais no espaço bidimensional. Tornava-se, portanto, pioneira no processo de produção de arte múltipla ou serial, posteriormente adotado também por Lygia Clark na serialização de seus Bichos.
} 
italiano encontra explicação na eterna "procura da forma e na sua valorização" (CALABRESE, 1987, p. 10).

Os escassos estudos desenvolvidos, até então, sobre a arte cinética produzida no passado recente e aquela que continua a ser elaborada por uma nova geração de artistas, ainda não geraram investigações que permitissem um aprofundamento e uma visão de conjunto sobre o tema, capazes de abarcar a verdadeira dimensão, abrangência e especificidade da obra dessa artista brasileira. Tampouco se especulou, ainda, sobre a possível contribuição ou mesmo contaminação entre os conceitos e postulados da arte cinética e outras linguagens artísticas, ou mesmo as tecnologias analógicas e digitais mais recentes A questão torna-se pertinente considerando que, no âmbito internacional, artistas cinéticos como Schöffer e Malina, depois de investirem na elaboração de obras cinéticas realizaram propostas ambientais inusitadas e complexas, mediante a utilização de computadores, circuitos de TV e raios laser, na década de 1960. De maneira similar alguns artistas brasileiros, como Waldemar Cordeiro, Maurício Salgueiro e Wesley Duke Lee, iriam conceber projetos interativos com funções programadas, nos quais hibridizaram fontes de luz, motores, microfones, semáforos, buzinas de automóvel, sirenes de ambulância, computadores, circuitos internos de TV, aparelhos para gravação a emissão de sons, entre outros.

\section{Referências}

ARAÚJO, Olívio Tavares de. Obra aberta ao povo. Veja, São Paulo, 8 ago. 1979. p. 118-9.

AULER, Hugo. Mary Vieira no espaço cultural. Correio Brasiliense, Brasília, 17 jul. 1977. Segundo Caderno.

BIHALJI-MERIN, Oto. La fin de I'Art à I'ère de la science? Bruxelles: La Connaissance, 1970.

BRITO, Ronaldo. Neoconcretismo. Rio de Janeiro: FUNARTE/INAP, 1985.

CALABRESE, Omar. A idade neobarroca. Tradução de Carmen de Carvalho e Artur Morão. São Paulo: Martins Fontes, 1988.

COUTINHO, Wilson. Mary Vieira criando beleza nas cidades. Jornal do Brasil , Rio de Janeiro, 26 ago. 1988.

GIL, José. Movimento total: o corpo e a dança. São Paulo: lluminuras, 2005.

PONTUAL, Roberto. Mary Vieira: o nascer da forma. Jornal do Brasil, Rio de Janeiro, 27 ago. 1976.

POPPER, Frank. Art, action et participation: I'artiste et la créativité aujourd'hui. Paris: Éditions Klincksieck, 1980.

POPPER, Frank. Arte Cinética. Artes, São Paulo, ano 3, n. 15, 1968.

SUBIRATS, Eduardo. Culturas virtuales. Madrid: Biblioteca Nueva, 2001. 
Da vanguarda ao pós-moderno. Tradução de: Luiz C. Daher e Adélia B. de Meneses. São Paulo: Nobel, 1984.

TAVARES, Célia L. Mary Vieira: o movimento como origem da forma, O Estado de Minas, Belo Horizonte, 15 jul. 1980.

TOMKINS, Calvin. Duchamp. Tradução de Maria Thereza Costa. São Paulo: Cosac Naify, 2004.

VIEIRA, Mary. Polivolumes: brinquedos plásticos do homem-criança. Jornal do Brasil, Rio de Janeiro, 17 ago. 1976.

Mary Vieira: linguagem internacional e espiritualidade brasileira. O Globo, Rio de Janeiro, 9 jul. 1976. 